\title{
A Cross Sectional Study of Physical Activity Profile among Undergraduate Medical Students
}

\author{
Dr. Shashiraj $\mathrm{HK}^{1}$, Dr. Kavitha BS ${ }^{2^{*}}$, Dr. Arifuddin $\mathrm{MK}^{2}$, Riyaz Ahmad Kalburgi ${ }^{3}$ \\ ${ }^{1}$ Associate Professor, Department of Physiology, Sri Siddhartha Medical College, Tumkur, India \\ ${ }^{2}$ Assistant Professor, Department of Physiology, Sri Siddhartha Medical College, Tumkur, India \\ ${ }^{3}$ Assistant Professor, Statistician, Department of Community Medicine, Sri Siddhartha Medical College, Tumkur, India
}

\author{
DOI: $\underline{10.36348 / \text { sijap.2020.v03i08.003 }}$ \\ | Received: 02.08.2020 | Accepted: 09.08.2020 | Published: 22.08.2020
}

*Corresponding author: Dr. Kavitha BS

\section{Abstract}

Background: Physical inactivity has been listed as one of the global health problem by WHO and is one of the important risk factor for development of non-communicable diseases like diabetes, cardiovascular illness and some malignancies. Regular physical activity plays a significant role in preventing the development of non-communicable diseases. Students of medicine in spite of having considerable knowledge about the benefits of physical activity the occurrence of physical inactivity is also common because of lack of time and busy academic schedule. Hence the present study was taken up to assess the background knowledge, barriers and motivational factors for the practice of physical activity and to study the pattern and duration of physical activity among first year medical students. Methods: A cross sectional study was conducted among 130 medical students. A pre-tested, semi-structured questionnaire was used to collect the data. Descriptional statistical analysis was done and results were expressed as percentages. Results: in our study majority of the students said they would like to practice some form of physical activities because of the health related benefits of the same. The pattern of physical activity practiced is mainly sports related which can be attributed to the younger age of the study population. Conclusion: we conclude that there is a greater need to encourage students to practice physical activities in some feasible form during their medical training so as to inculcate good practice of regular physical activities into their own lifestyle and advice their future patients regarding the health benefits of regular practice of physical activity.

Keywords: Medical students, physical activity.

Copyright @ 2020: This is an open-access article distributed under the terms of the Creative Commons Attribution license which permits unrestricted use, distribution, and reproduction in any medium for non-commercial use (NonCommercial, or CC-BY-NC) provided the original author and source are credited.

\section{INTRODUCTION}

Physical activity which is often used interchangeable with exercise is defined by WHO as any bodily movements produced by skeletal muscle that requires expenditure of energy and exercise is also a subset of physical activity [1].

Practice of regular physical activity is very important for a person to stay healthy, to control body weight $\&$ also to reduce the risk of development of lifestyle diseases like Essential hypertension, Type II diabetes mellitus or even prevention of development of some cancers [2].

Physical inactivity has been listed as one of the global health problem by WHO which is supposed to increase overall morbidity and mortality. According to 2016 data by WHO $28 \%$ of adults that is above 18 years of age are insufficiently physically active. The Same data also reveals $81 \%$ of school going children aged between 11 to 17 years practice less than 60 minutes of moderate to vigorous intensity physical activity daily [3]. In a study done by HA Alzamil et al indicate that unhealthy lifestyle habits including physical inactivity is more prevalent among college going females which warrants the behavioural intervention to enhance the health and wellbeing of female college students [4]. In a study done by ICMR and India Diabetes (ICMRINDIAB) which was conducted across 4 regions of India showed that $54.4 \%$ of study population were inactive with fewer than $10 \%$ engaging in recreational physical activity(5). It is a known fact that physical inactivity increases the burden of onset of noncommunicable diseases in the community. WHO has set a global target to reduce the prevalence of insufficient physical activity by $10 \%$ by the year 2025 [6]. 
Physical Inactivity (lack of physical activity) has been identified as the fourth leading risk factor for global mortality ( $6 \%$ of deaths globally). Moreover physical inactivity is estimated to be the main cause for approximately $21-25 \%$ of breast and colon cancers, $27 \%$ of diabetes and approximately $30 \%$ of ischemic heart disease burden [7].

The current recommendation of practice of physical activity is to engage in a minimum of 150 minutes of moderate intensity aerobic activity or the practice 75 minutes of vigorous intensity physical activity per week [8].

Behaviour of students during college life although temporary but unhealthy practices picked up during this course can persist throughout their life and lead to health consequences [9].

It is assumed that students of medicine have considerable knowledge about the practice of physical activity and its benefits and also the risk associated with physical inactivity, unhealthy dietary habits and sedentary lifestyle [10].

It is a well-known fact that there exists a direct correlation between the physical activity practiced among medical students and the advice they provide to their patients. But there is no evidence to indicate that the knowledge about it translates into practice of physical activity to maintain good health [10-13].

Physical inactivity is also common in medical students because of lack of time, due to academic activity \& busy schedules. These days with the increase usage of smartphones the time spent on physical activity is reduced leading to physical inactivity among medical students [14].

So it becomes important for the future doctors for themselves to be physically active and promote the importance of physical activity \& to educate the community regarding the risk associated with physical inactivity $[15,16]$. It is assumed that it is very important to do a quantitative assessment of physical activity and various other factor influencing it as early as in the first year of medical course so that the students realize the benefits of regular practice of physical activity \& incorporate these changes to the daily lifestyle which would benefit them throughout the course and further.

With this background this current study has been taken up to

1. To assess the practice of physical activity among first year medical students.

2. To assess the background knowledge regarding physical activity.

3. To understand any barriers and look at the motivational factors for practice of physical activity among first year medical students.

\section{METHODS}

This is a cross sectional study which was conducted among first year medical students of the year 2018-19 at Sri Siddhartha Medical College which is a constituent college of Sri Siddhartha Academy of Higher Education deemed to be University which caters to students from all over the country and worldwide. The institution promotes the practice of physical activity among students by providing the required infrastructure like playground \& space for various indoor activities. A pre-tested, semi-structured questionnaire was devised \& administered to all the first year medical students after the purpose of the study was clearly explained to the participants. The questionnaire included general information of the study subjects like age \& gender \& also questions about perceptions \& barrier about physical activity were included. Physical activity practices were measured by using international physical activity questionnaire (IPAQ) (17). The short version of IPAQ which has 7 questions which enquires about the time spent on physical activity for the last 7 days was used for this study. The study subjects included all the 130 students of I MBBS. After obtaining the institutional ethics committee approval \& explaining the purpose of the study to the subjects the questionnaire along with written informed consent forms were distributed to them, filled forms were collected. 


\section{RESULTS}

Table-1: Knowledge and perception about benefits of Physical activity $n=130$

\begin{tabular}{|c|c|}
\hline Perception & $\mathbf{N}(\%)$ \\
\hline \multicolumn{2}{|c|}{ Physical activity helps in prevention of } \\
\hline Obesity & $126(96.9)$ \\
\hline Coronary artery disease & $117(90)$ \\
\hline Hypertension & $126(96.9)$ \\
\hline Diabetes & $96(73.84)$ \\
\hline Stroke & $71(54.61)$ \\
\hline Osteoporosis & $26(20)$ \\
\hline Others & $7(5.38)$ \\
\hline \multicolumn{2}{|l|}{ Others like $(\mathrm{n}=42)$} \\
\hline To get good sleep & $22(52.38)$ \\
\hline Avoid stress & $12(28.57)$ \\
\hline To avoid depression & $8(19.04)$ \\
\hline \multicolumn{2}{|c|}{ Perceived benefits of Physical activity } \\
\hline Keeps me fresh & $110(84.6)$ \\
\hline To burn excess calories & $125(96.15)$ \\
\hline Reduce stress & $96(73.84)$ \\
\hline Improves my memory & $52(40)$ \\
\hline Others & $10(7.69)$ \\
\hline \multicolumn{2}{|l|}{ Others like $(n=13)$} \\
\hline Better sleep & $7(53.84)$ \\
\hline Keeps me fit & $6(46.15)$ \\
\hline \multicolumn{2}{|c|}{ Like to do Physical activity } \\
\hline Yes & $102(78.42)$ \\
\hline No & $16(12.3)$ \\
\hline No response & $12(9.23)$ \\
\hline
\end{tabular}

Table-2: Practice and Motivation for Physical activity

\begin{tabular}{|l|l|}
\hline Practice & N (\%) \\
\hline If no (n=73), reasons & $45(61.64)$ \\
\hline No time & $17(23.28)$ \\
\hline Affect studies & $2(2.73)$ \\
\hline No space & $9(12.32)$ \\
\hline No response & $22(38.59)$ \\
\hline If yes, reasons (n=57) & $6(10.52)$ \\
\hline Burn calories & $9(15.78)$ \\
\hline Mental peace & $20(35.08)$ \\
\hline Increases stamina & $106(81.53)$ \\
\hline Keeps me fit & $91(70)$ \\
\hline Motivation & $54(41.53)$ \\
\hline To be fit \& healthy & $44(33.84)$ \\
\hline To reduce weight
\end{tabular}

Table-3: Pattern and duration of Physical activity ( $n=)$

\begin{tabular}{|l|l|}
\hline Pattern and Duration & $\mathbf{N}(\boldsymbol{\%})$ \\
\hline Playing games & $74(56.92)$ \\
\hline Jogging & $47(36.15)$ \\
\hline Swimming & $24(18.46)$ \\
\hline Cycling & $18(13.84)$ \\
\hline Gym & $61(46.92)$ \\
\hline Others & $20(15.38)$ \\
\hline Others like $(\mathrm{n}=45)$ & $5(11.11)$ \\
\hline Skipping & $13(28.88)$ \\
\hline Dancing & $11(24.44)$ \\
\hline Aerobics & $16(35.55)$ \\
\hline Exercise & $24(18.46)$ \\
\hline Duration (years) & $20(15.38)$ \\
\hline$<1$ & $34(26.15)$ \\
\hline $1-2$ & $48(36.92)$ \\
\hline $2-5$ & $4(3.07)$ \\
\hline $5-10$ & \multicolumn{2}{|l}{} \\
\hline No response &
\end{tabular}

\section{DISCUSSION}

The practice of regular physical activity is an essential component of healthy lifestyle \& is important for physical, mental \& social wellbeing of a person. Our study was taken up to evaluate the knowledge background of students regarding the benefits of physical activity \& to assess various perceptions \& the barriers as perceived by the students for the practice of regular physical activity. Pattern and duration of physical activity was also assessed.

Table 1 shows the background knowledge and perception regarding the benefits of physical activity. The study population believes that the practice of regular physical activity helps in prevention of obesity (96.9\%), Hypertension (96.9\%), coronary artery disease (90\%), diabetes mellitus $(73.84 \%)$, stroke $(54.61 \%)$, osteoporosis $(20 \%)$ and a small percentage say that practice of regular physical activity helps them to get good sleep, avoid stress \& to avoid depression. The findings of our study are in concordance with a similar study done by Kumar, et al. at Kasturba Medical College Mangalore [18].

The perceived benefits of physical activity by the study population are that physical activity helps them to keep fresh, burn excess calories, reduce stress and improvement of memory. In a study done by Rees et al. has shown that physical activity is used as a tool to relive stress and for enjoyment [19]. A small percentage of the study group opine that the regular physical activity keeps them fit and induces better sleep. $78.46 \%$ of the study population quote that they like to do some form of physical activity keeping in mind the above mentioned perceived benefits of Physical activity. Similar findings have also been noted by a study done by Kumar et al. in 2014 [18]. 
Table 2 depicts the practice and the motivating factors for physical activity. Our study shows that the motivational factors for practice of physical activity include staying fit \& healthy $(81.53 \%)$, to reduce weight $(70 \%)$, to increase muscle mass $(41.53 \%)$, to increase flexibility and strength $(33.84 \%)$.

The reasons quoted by the study population for practice of physical activity includes burning calories, maintain mental peace and increase stamina. The barriers for practice of physical activity as perceived by the study population include shortage or no time and $23.28 \%$ of the study population believes that it will affect their academic activities; hence they believe it has the major barrier for the practice of physical activity.

Table 3 shows the pattern and duration of the physical activity. The pattern of physical activity includes playing games (56.92\%), gym (46.92\%), jogging (36.15\%), swimming (18.46\%), cycling $(13.84 \%)$. other pattern of physical activity include skipping, dancing and aerobics. Since our study population includes young individuals aged between 18 to 20 years the form of physical activity practice is mainly sports related and the duration pattern shows that they have been practising physical activity during their pre university years of education.

\section{CONCLUSION}

Our study shows that majority of the students would like to practice some form of physical activities and they believe that health related benefits as the main reason for the practice of the same. The knowledge about perceived benefits of physical activity is good among medical students and few in the study group also believe that the practice of the physical activity helps them to avoid stress and mood fluctuations. With this study we conclude that there is a greater need to encourage students to practice physical activities in some feasible form during their medical training so as to inculcate good practice of regular physical activities into their own lifestyle and advice their future patients regarding the health benefits of regular practice of physical activity.

\section{RECOMMENDATIONS}

We also recommend to the policy makers of the university to incorporate the regular practice of physical activity as a part of University curriculum keeping in mind the perceived benefits of physical activity.

\section{REFERENCES}

1. World Health Organization. (2018). Factsheet: physical activity. Available at: https://www.who.int/ news-room/factsheets/detail/physical-activity. Accessed on 14 July 2017.
2. Al-Asousi, M., \& El-Sabban, F. (2016). Physical activity among preclinical medical students at the University of Malaya, Malaysia. Age, 20(20), 119.

3. Samitz, G., Egger, M., \& Zwahlen, M. (2011). Domains of physical activity and all-cause mortality: systematic review and dose-response meta-analysis of cohort studies. International journal of epidemiology, 40(5), 1382-1400.

4. Alzamil, H. A., Alhakbany, M. A., Alfadda, N. A., Almusallam, S. M., \& Al-Hazzaa, H. M. (2019). A profile of physical activity, sedentary behaviors, sleep, and dietary habits of Saudi college female students. Journal of family \& community medicine, 26(1), 1.

5. ICMR-INDIAB study (Phase-1) [ICMR-INDIAB5]. (2014). Int J Behav Nutr Phys Act 11, 26.

6. World Health Organization. (2014). Global status report on communicable diseases 2014. Geneva, Switzerland.

7. Liu, L., Shi, Y., Li, T., Qin, Q., Yin, J., Pang, S., \& Wei, S. (2016). Leisure time physical activity and cancer risk: evaluation of the WHO's recommendation based on 126 high-quality epidemiological studies. British journal of sports medicine, 50(6), 372-378.

8. World Health Organization. Global Recommendations on Physical Activity for Health. Geneva, Switzerland: WHO; 2010.

9. Silliman, K., Rodas-Fortier, K., \& Neyman, M. (2004). Survey of dietary and exercise habits and perceived barriers to following a healthy lifestyle in a college population. Californian journal of health promotion, 2(2), 10-19.

10. Lobelo, F., Duperly, J., \& Frank, E. (2009). Physical activity habits of doctors and medical students influence their counselling practices. British journal of sports medicine, 43(2), 89-92.

11. Frank, E., Galuska, D. A., Elon, L. K., \& Wright, E. H. (2004). Personal and clinical exercise-related attitudes and behaviors of freshmen US medical students. Research quarterly for exercise and sport, 75(2), 112-121.

12. Stanford, F. C., Durkin, M. W., Blair, S. N., Powell, C. K., Poston, M. B., \& Stallworth, J. R. (2012). Determining levels of physical activity in attending physicians, resident and fellow physicians and medical students in the USA. British journal of sports medicine, 46(5), 360-364.

13. Duperly, J., Lobelo, F., Segura, C., Sarmiento, F., Herrera, D., Sarmiento, O. L., \& Frank, E. (2009). The association between Colombian medical students' healthy personal habits and a positive attitude toward preventive counseling: crosssectional analyses. BMC public Health, 9(1), 218.

14. Oberg, E. B., \& Frank, E. (2009). Physicians' health practices strongly influence patient health practices. The journal of the Royal College of Physicians of Edinburgh, 39(4), 290. 
15. Rogers, L. Q., Bailey, J. E., Gutin, B., Johnson, K. C., Levine, M. A., Milan, F., \& Sherman, S. E. (2002). Teaching resident physicians to provide exercise counseling: a needs assessment. Academic Medicine, 77(8), 841-844.

16. Ekelund, U., Sepp, H., Brage, S., Becker, W., Jakes, R., Hennings, M., \& Wareham, N. J. (2006). Criterion-related validity of the last 7-day, short form of the International Physical Activity Questionnaire in Swedish adults. Public health nutrition, 9(2), 258-265.

17. Kumar, H., Ramakrishnan, N., Chandrashekar, M., Kodihdl, A., Jayaramegowda, A.K., Kadian, M.,
Chauhan, V. (2014). A cross-sectional study on patterns, motivating factors and barriers for physical activity among undergraduate medial students. Inter J Med Public Health, 41(4), 413416.

18. Rees, R., Kavanagh, J., Harden, A., Shepherd, J., Brunton, G., Oliver, S., \& Oakley, A. (2006). Young people and physical activity: a systematic review matching their views to effective interventions. Health education research, 21(6), 806-825. 